\title{
An Investigation of Possibility of Using Hydraulic Fracturing Proppants as Supports for Deep Oxidation Catalysts Employed in the Fluidized Bed
}

\author{
Aleksandr V. Fedorov*a,b, \\ Dmitry Yu. Ermakova, Nikolay A. Yazykova, \\ Yuliya K. Gulyaeva ${ }^{a}$ and Vadim A. Yakovleva \\ ${ }^{a}$ Boreskov Institute of Catalysis SB RAS \\ 5 Akademik Lavrentiev, Novosibirsk, 630090, Russia \\ ${ }^{b}$ Novosibirsk State University \\ 2 Pirogova Str., Novosibirsk, 630090, Russia
}

Received 10.09.2018, received in revised form 12.09.2018, accepted 16.11.2018

\begin{abstract}
In this work, a possibility of using hydraulic fracturing proppants (HFP) as supports for deep oxidation catalysts, employed in the fluidized bed catalytic combustion, was considered. Two methods based on leaching with alkali solution were used to increase a specific surface area of HFP. The samples were characterized by physico-chemical methods (XPS, XRD, low-temperature nitrogen adsorption). $\mathrm{CuCr}$ containing catalysts, based on HFP and obtained by the wet-impregnation method, and industrial catalysts were tested in the process of combustion brown coal in fluidized bed. It was shown that catalysts based on HFP allow us to reach a high degree of burnout (95\%) which typical for industrial catalysts and higher than in the case when using an inert material (70\%).
\end{abstract}

Keywords: heterogeneous catalysts, fluidized bed, CO oxidation.

Citation: Fedorov A.V., Ermakov D.Yu., Yazykov N.A., Gulyaeva Yu.K., Yakovlev V.A. An investigation of possibility of using hydraulic fracturing proppants as supports for deep oxidation catalysts employed in the fluidized bed, J. Sib. Fed. Univ. Chem., 2018, 11(4), 477-487. DOI: 10.17516/1998-2836-0092.

(C) Siberian Federal University. All rights reserved

* Corresponding author E-mail address: fedorov@catalysis.ru 


\title{
Исследование пропанта в качестве носителя катализаторов глубокого окисления \\ для кипящего слоя
}

\author{
А.В. Федоров ${ }^{\text {a, }}$, Д.Ю. Ермаков ${ }^{\mathrm{a}}$, \\ Н.А. Языков ${ }^{a}$ Ю.К. Гуляева ${ }^{a}$, В.А. Яковлев ${ }^{a}$ \\ ${ }^{a}$ Институт катализа СО РАН \\ Россия, 630090, Новосибирск, пр. Академика Лаврентьева, 5 \\ ${ }^{6}$ Новосибирский национальный \\ исследовательский государственный университет \\ Россия, 630090, Новосибирск, ул. Пирогова, 2
}

В работе рассмотрена возможность использования пропанта в качестве носителя катализаторов глубокого окисления, применяемых для проведения процессов в кипящем слое. Предложено два способа развития удельной поверхности, основанных на выщелачивании в водных растворах гидроксида натрия. Исходный и модифицированные пропанты были исследованы комплексом физико-химических методов, включая низкотемпературную адсорбцию $N_{2}$, РФА, РФЭС. Медно-хромовые катализаторы на основе пропанта были получены методом пропитки по влагоемкости. Образиы катализаторов на основе пропанта и промышленные катализаторы (ЩКЗ-1, ИК-12-73, ИК-12-74А) были испытаны в процессе сжигания бурого канско-ачинского угля. Показано, что применение катализаторов на основе пропанта позволяет достичь высокой степени выгорания бурого угля (95\%), характерной для промышленных катализаторов, что значительно выше, чем при использовании инертного материала (70\%).

Ключевые слова: гетерогенные катализаторы, кипящий слой, окисление СО.

\section{Введение}

Постоянный рост энергопотребления в условиях увеличения цен на все виды традиционных топливных ресурсов делает привлекательным вовлечение ранее не использовавшихся низкосортных топлив, включая техногенные твердые органические отходы и возобновляемую биомассу. При использовании низкосортных твердых топлив важно учитывать экологический фактор - количество выбросов в атмосферу токсичных веществ. Также существенным аспектом является экономное использование топлива. При слоевом или факельном сжигании твердого топлива (температура процесса $1200-1600{ }^{\circ} \mathrm{C}$ ) заметный недостаток технологий значительное загрязнение атмосферы вредными выбросами $\left(\mathrm{NO}_{\mathrm{x}}, \mathrm{SO}_{\mathrm{x}}, \mathrm{CO}\right.$, бензпирены), существенно превышающими санитарные нормы. Использование технологии сжигания топлив в кипящем слое инертного материала позволяет снизить температуру ведения процесса до 800-1000 ${ }^{\circ} \mathrm{C}$, однако уровень загрязнения атмосферы вредными веществами остается высоким [1]. 
В Институте катализа СО РАН разработана нетрадиционная технология сжигания различных топлив и отходов в кипящем слое катализатора [2]. Данная технология позволяет в значительной мере ликвидировать недостатки традиционных способов сжигания как в факеле, так и в кипящем слое инертного материала. Технология основана на использовании кипящего слоя частиц катализатора с совмещением тепловыделения и теплоотвода в едином псевдоожиженном слое при соотношении воздуха и топлива, близком к стехиометрическому $[3,4]$.

Одним из сдерживающих недостатков данного способа является значительное истирание и унос катализатора в процессе его эксплуатации в кипящем слое. Для уменьшения потерь катализатора для его приготовления используют упрочненные носители на основе оксида алюминия, получаемые по сложным технологиям. Поэтому поиск альтернативного носителя, который будет удовлетворять всем требованиям, предъявляемым к носителям катализаторов глубокого окисления для кипящего слоя, актуальная задача. Одним из подходов в решении этой задачи служит использование высокопрочного пропанта.

В настоящей работе была исследована возможность применения в качестве носителя для катализаторов глубокого окисления пропанта и модифицированных пропантов, полученных с использованием различных способов увеличения их удельной поверхности. Были приготовлены и исследованы медно-хромовые катализаторы на основе пропанта в реакции окисления $\mathrm{CO}$ и в сжигании бурого угля в кипящем слое. Полученные катализаторы были исследованы комплексом физико-химических методов.

\section{Материалы и методы}

В работе использовали коммерческий пропант компании ООО “ФОРЭС" (состав: $\mathrm{SiO}_{2}-$ $56,8 \% ; \mathrm{MgO}-32,6 \% ; \mathrm{Fe}_{2} \mathrm{O}_{3}-5,1 \% ; \mathrm{Al}_{2} \mathrm{O}_{3}-2,8 \%$ масс.) [5]. Для увеличения удельной поверхности была приготовлена серия модифицированных пропантов путем выщелачивания в избытке водного раствора гидроксида натрия:

- в мягких условиях $\left(3.5 \mathrm{M} \mathrm{NaOH}, 95^{\circ} \mathrm{C}\right)$ серия ПМ ${ }^{1}$;

- в жестких условиях $\left(18.0 \mathrm{M} \mathrm{NaOH}, 120^{\circ} \mathrm{C}\right)$ серия ПМ ${ }^{2}$.

После проведения процесса выщелачивания пропант обрабатывали избытком $0.5 \mathrm{M}$ раствора азотной кислоты и прокаливали при $700{ }^{\circ} \mathrm{C}$ в течение 1 ч.

Медно-хромовые катализаторы готовились методом пропитки по влагоемкости концентрированным раствором бихромата меди с последующей сушкой при температуре $100{ }^{\circ} \mathrm{C}$ в течение 1 ч и прокалкой при температуре $700{ }^{\circ} \mathrm{C}$ в течение 2 ч.

Образцы носителей и катализаторов были исследованы комплексом физико-химических методов (РФА, РФЭС, низкотемпературная адсорбция азота, прочность на раздавливание (прибор МП-9С) и истирание (ASTMD-4058)). Каталитические свойства были исследованы в реакции импульсного окисления СО и в процессе сжигания бурого угля. Подробное описание оборудования и экспериментальных установок приведено в работе [6].

\section{Результаты и обсуждения}

\section{Исследование физико-химических характеристик пропанта}

Пропант представляет собой гранулированный материал, который используется в нефтедобывающей промышленности. Такие преимущества, как высокая механическая прочность

$$
\text { - } 479 \text { - }
$$


( $\mathrm{P}_{\mathrm{cp}} \sim 90$ МПа), сферическая форма гранул, низкая стоимость, делают пропант очень перспективным носителем для катализаторов, предназначенных для проведения процессов в кипящем слое. Однако малая удельная поверхность пропанта не позволяет напрямую использовать его в качестве носителя для катализаторов.

Размер гранул пропанта варьируется в диапазоне 2,0-3,0 мм, а насыпной вес составляет 1,52 г/мл. Стоит отметить очень низкое значение удельной поверхности ( 0,5 м²/г по БЭТ) пропанта, что, несомненно, скажется на активности медно-хромового катализатора, полученного на его основе. Исходный пропант был исследован методом РФА (рис. 1). Определение фазового состава образца пропанта показало преимущественное содержание кварца ( $\mathrm{SiO}_{2} \sim 50$ \%), присутствие двух фаз силикатов магния в виде энстатита $\left(\mathrm{MgSiO}_{3} \sim 30 \%\right)$ и форстерита $\left(\mathrm{Mg}_{2} \mathrm{SiO}_{4}\right.$ $\sim 10$ \%). Остальное приходится на смешанные оксиды алюминия, железа, магния.

\section{Способы развития удельной поверхности пропанта}

Исследование процесса растворения пропанта в разбавленных и концентрированных растворах неорганических кислот $\left(\mathrm{HNO}_{3}, \mathrm{H}_{2} \mathrm{SO}_{4}, \mathrm{HCl}\right)$ показало, что растворение пропанта не происходит в этих кислотах, что обусловлено составом пропанта. Общеизвестно, что из неорганических кислот только плавиковая кислота растворяет оксид кремния. Поэтому стоит ожидать, что пропант будет растворяться в растворе плавиковой кислоты, но из-за высокой токсичности и летучести HF ее использование не технологично и поэтому не применялось в данной работе.

Эксперименты по растворению пропанта в расплаве щелочи $\left(\mathrm{KOH}, 450{ }^{\circ} \mathrm{C}\right)$ показали, что гранулы в процессе растворения подвергаются разрушению и в конечном итоге приобрета-

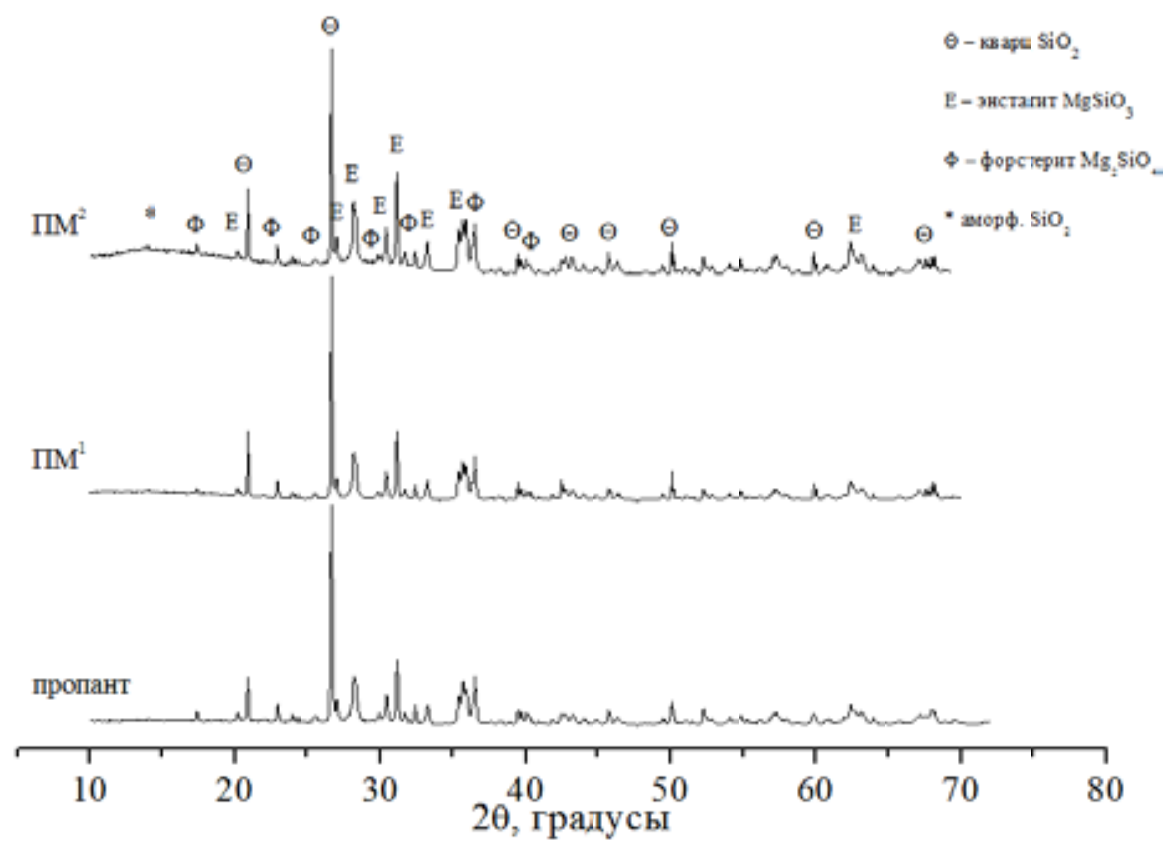

Рис. 1. Рентгенограмма образцов исходного и модифицированных пропантов

Fig. 1. XRD of original and modified proppants 
ют неправильную сферическую форму. При этом не наблюдалось значительного увеличения удельной поверхности. В связи с этим дальнейшая модификация пропанта проводилась в более мягких условиях выщелачивания для получения развитой удельной поверхности.

Для увеличения удельной поверхности пропанта в настоящей работе использовали два типа условий выщелачивания, позволяющих сохранить сферическую форму гранул: мягкие (3.5 M NaOH, $\left.95{ }^{\circ} \mathrm{C}\right)$ и жесткие $\left(18.0 \mathrm{M} \mathrm{NaOH}, 120{ }^{\circ} \mathrm{C}\right)$. При этом в последнем случае стоит ожидать более интенсивного растворения фаз силикатов магния и смешанных оксидов. В частности, при этом должно происходить растворение соединений магния, например, по реакции [7]

$$
\mathrm{MgSiO}_{3}+4 \mathrm{NaOH} \rightleftarrows \mathrm{Na}_{2} \mathrm{SiO}_{3}+\mathrm{Na}_{2}\left[\mathrm{Mg}(\mathrm{OH})_{4}\right]
$$

\section{Выщелачивание пропанта в мягких условиях}

На рис. 2 представлена зависимость удельной поверхности модифицированных пропантов и потери массы от времени обработки раствором щелочи, полученная в мягких условиях. Видно, что максимальная степень выщелачивания пропанта при растворении в таких условиях составляет $\sim 10$ масс. \%. При этом оптимальное время проведения процесса выщелачивания, при котором достигается максимальная степень выщелачивания, равно 20 ч. На графике также видно, что удельная поверхность модифицированных пропантов коррелирует со степенью выщелачивания.

Активность медно-хромовых катализаторов на основе модифицированных пропантов была исследована в реакции окисления СО (рис. 3). Видно, что, как и в случае с удельной поверхностью, по показателю температуры 50 \% конверсии СО оптимальное время выщелачивания составляет 20 ч (далее катализатор $\mathrm{CuCr}_{2} \mathrm{O}_{4} / \Pi M^{1}$ ).

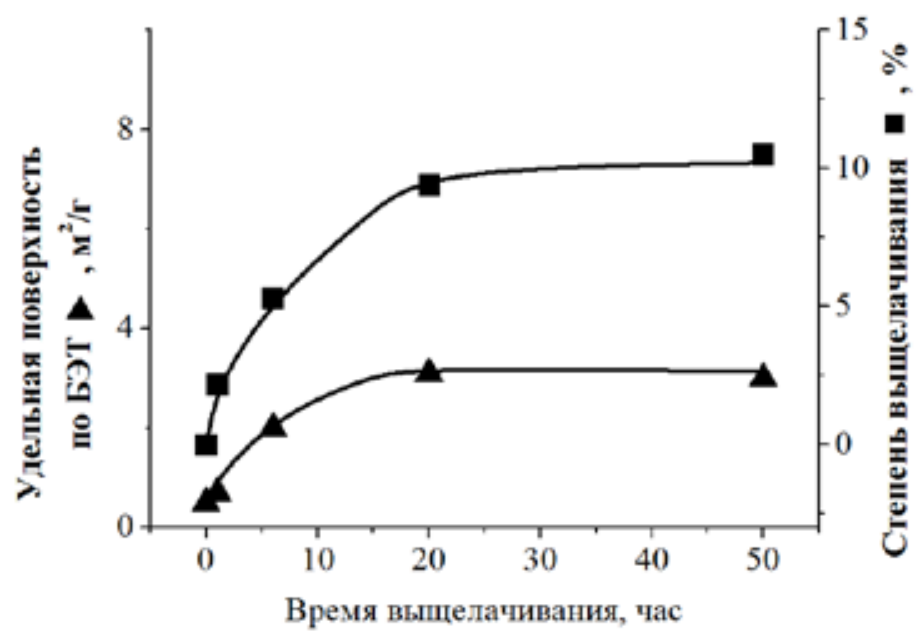

Рис. 2. Зависимость степени выщелачивания и значения удельной поверхности от времени выщелачивания в мягких условиях

Fig. 2. The dependence of the degree of leaching and the value of the specific surface on the leaching time under mild conditions 


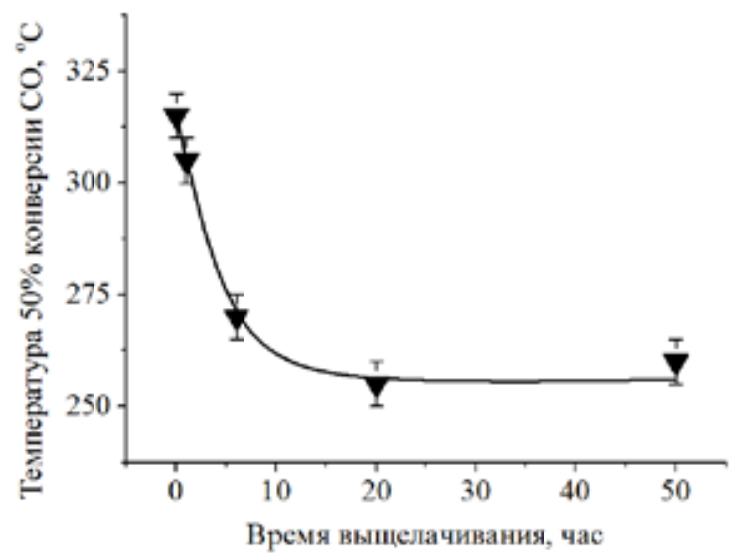

Рис. 3. Зависимость активности медно-хромовых катализаторов на основе пропанта от времени выщелачивания

Fig. 3. The dependence of the catalytic activities of $\mathrm{CuCr}$-containing catalysts, based on proppants, on the leaching time

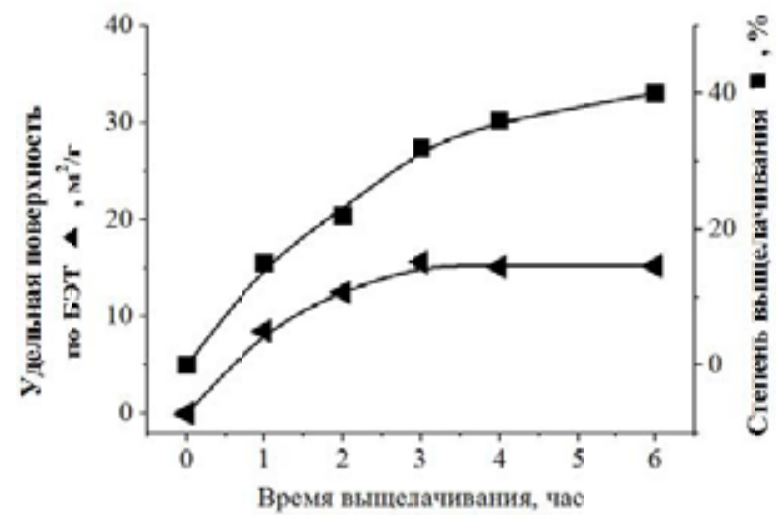

Рис. 4. Зависимость степени выщелачивания и значения удельной поверхности от времени выщелачивания в жестких условиях

Fig. 4. The dependence of the degree of leaching and the value of the specific surface on the leaching time under tough conditions

\section{Выщелачивание пропанта в жестких условиях}

Зависимость удельной поверхности модифицированных пропантов и потери массы от времени обработки раствором щелочи в жестких условиях приведена на рис. 4. Видно, что, несмотря на непрерывное увеличение потери массы, значение удельной поверхности модифицированного пропанта после 3 ч выщелачивания остается постоянным и равно $~ 15$ м²/г.

В табл. 1 приведены данные по каталитической активности медно-хромовых катализаторов на основе исходного и модифицированного пропантов (время выщелачивания 3 ч). Из представленных данных видно, что активность катализаторов $\mathrm{CuCr}_{2} \mathrm{O}_{4} / \Pi \mathrm{M}^{2 *}$ (образец пропанта не подвергался обработке раствором азотной кислоты) значительно ниже, чем активность меднохромового катализатора на основе исходного пропанта, несмотря на более высокое значение удельной поверхности исходного носителя. Такое низкое значение активности, вероятно, связа- 
но с наличием на поверхности носителя ПМ ${ }^{2 *}$ соединений $\mathrm{Mg}, \mathrm{Fe}, \mathrm{Al}$, которые взаимодействуют с активным компонентом на стадии приготовления катализатора с образованием менее активных в реакциях глубокого окисления фаз, например $\mathrm{MgCr}_{2} \mathrm{O}_{4}$. Стоит отметить, что обработка пропанта азотной кислотой приводит к значительному повышению значения как удельной поверхности, так и активности медно-хромовых катализаторов, получаемых на его основе.

\section{Исследование физико-химических характеристик}

\section{модифицированных пропантов}

Образцы исходного и модифицированных пропантов $\left(\Pi^{1}\right.$ и ПМ' $\left.{ }^{2}\right)$ были исследованы методом РФЭС. Значения энергии связи $\mathrm{Si} 2 p$ и O1s для гранул и порошков пропантов, а также значения относительных поверхностных концентраций представлены в табл. 2. Известно, что значение энергий связи $\mathrm{Si} 2 p$ для $\mathrm{Si}^{4+}$ изменяется в диапазоне от 102,1 до 103,0 эВ [8-11]. Меньшее значение характерно для кремния в составе силикатов $\left(\mathrm{Si}^{4+}\right)$, большее - для $\mathrm{SiO}_{2}$. При этом для образцов исходного ПМ ${ }^{1}$ и ПМ² энергия связи $\mathrm{Si} 2 p$ составляет 102,1-102,2 эB, 102,4 и 102,9-103,0 эВ соответственно. Аналогичный сдвиг присутствует и для пика Ols. Стоит отметить, что при этом не наблюдается существенного уширения линий $\mathrm{Si} 2 p$ и О1s. Следовательно, можно пред-

Таблица 1. Физико-химические характеристики медно-хромовых катализаторов на основе пропанта Table 1. Physico-chemical characteristics of copper-chromium catalysts based on proppant

\begin{tabular}{|l|c|c|c|}
\hline \multicolumn{1}{|c|}{ Образец } & $\begin{array}{c}\text { Удельная поверхность } \\
\text { носителя по БЭТ, } \mathrm{M}^{2} / \Gamma\end{array}$ & $\begin{array}{c}\text { Содержание активного } \\
\text { компонента, \% вес. }\end{array}$ & $\begin{array}{c}\text { Температура 50 \% } \\
\text { конверсии СО, }{ }^{\circ} \mathrm{C}\end{array}$ \\
\hline $\mathrm{CuCr}_{2} \mathrm{O}_{4} /$ пропант & 0,5 & 2,8 & 315 \\
\hline $\mathrm{CuCr}_{2} \mathrm{O}_{4} / \Pi \mathrm{M}^{2}$ & 15,6 & 5,2 & 210 \\
\hline $\mathrm{CuCr}_{2} \mathrm{O}_{4} / \Pi \mathrm{M}^{2 *}$ & 4,8 & 6,3 & 335 \\
\hline $\mathrm{CuCr}_{2} \mathrm{O}_{4} / \Pi \mathrm{M}^{1}$ & 4,5 & 5,3 & 255 \\
\hline
\end{tabular}

* После выщелачивание образец модифицрованного пропанта не был обработан избытком раствора азотной кислоты.

Таблица 2. Значение энергии связи $\mathrm{Si} 2 p, \mathrm{O} 1 s$ и относительные поверхностные концентрации атомов для образцов пропантов

Table 2. The value of the binding energy of $\mathrm{Si} 2 p, \mathrm{O} l s$ and the relative surface concentrations of atoms for samples of proppants

\begin{tabular}{|c|c|c|c|c|c|c|}
\hline \multirow{2}{*}{ Образец } & \multirow{2}{*}{ Вид } & \multicolumn{2}{|c|}{ Значения энергии связи, эВ } & \multicolumn{2}{|c|}{$\begin{array}{c}\text { Относительные } \\
\text { поверхностные } \\
\text { концентрации }\end{array}$} & $\begin{array}{c}\text { Si } 2 p / \\
\text { O1s } \\
\text { FWHM }\end{array}$ \\
\cline { 3 - 7 } & & $\mathrm{Si} 2 p$ & $\mathrm{O} 1 s$ & {$[\mathrm{Mg}] /[\mathrm{Si}]$} & {$[\mathrm{Na}] /[\mathrm{Si}]$} & \\
\hline Пропант & Гранула & 102,4 & 531,6 & 0,46 & 0,019 & $2,1 / 2,7$ \\
\hline Пропант & Порошок & 102,4 & 531,6 & 0,59 & - & $2,2 / 2,6$ \\
\hline$\Pi^{1}$ & Гранула & 102,1 & 531,4 & 0,21 & 0,075 & $2,4 / 2,9$ \\
\hline$\Pi^{1}$ & Порошок & 102,2 & 531,5 & 0,49 & 0,066 & $2,2 / 2,8$ \\
\hline$\Pi^{2}$ & Гранула & 102,9 & 532,2 & 0,33 & 0,053 & $2,3 / 2,7$ \\
\hline$\Pi^{2}$ & Порошок & 103,0 & 532,3 & 0,27 & 0,053 & $2,3 / 2,6$ \\
\hline
\end{tabular}


Таблица 3. Результаты исследования механической прочности

Table 3. The results of the study of mechanical strength

\begin{tabular}{|c|c|c|}
\hline \multirow[t]{2}{*}{ Образец } & \multirow{2}{*}{$\begin{array}{c}\text { Потеря массы при истирании, \% } \\
\text { (метод ASTMD-4058) }\end{array}$} & $\begin{array}{c}\text { Механическая прочность на } \\
\text { раздавливание (прибор МП-9С), МПа }\end{array}$ \\
\hline & & сред. \\
\hline $\mathrm{CuCr}_{2} \mathrm{O}_{4} / \Pi \mathrm{M}_{1} 700$ & $<1(0,5)$ & 52 \\
\hline $\mathrm{CuCr}_{2} \mathrm{O}_{4} / \Pi \mathrm{M}_{2} \mathrm{M}^{* *}$ & $<1(0,7)$ & 28 \\
\hline $\mathrm{CuCr}_{2} \mathrm{O}_{4} /$ пропант & $<1(0,2)$ & 86 \\
\hline
\end{tabular}

положить, что на поверхности образца ПМ'1 кремний находится преимущественно в виде силикатов, а в образце ПМ' - преимущественно в виде $\mathrm{SiO}_{2}$.

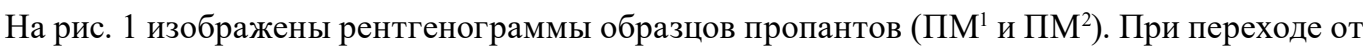
исходного пропанта к модифицированным образцам состав практически не меняется и представляет собой фазы кварца и силиката магния (энстатита и форстерита). Тем не менее в рентгенограмме образца ПМ² наблюдается увеличение интенсивности в областях углов $2 \theta \sim 10-30^{\circ}$, что свидетельствует о присутствии в образце аморфной фазы, вероятно $\mathrm{SiO}_{2}$ [12].

По совокупности физико-химических характеристик можно предположить, что в процессе получения образца ПМ' на стадии выщелачивания происходит растворение преимущественно кварца с поверхности пропанта, поэтому кремний на поверхности модифицированного пропанта находится в виде силикатов, что подтверждается результатами РФЭС исследования. В случае с образцом ПМ 2 , согласно данным РФЭС и РФА, происходит формирование аморфной фазы $\mathrm{SiO}_{2}$, которая способствует увеличению удельной поверхности пропанта. В данном случае фактически происходит переосаждение соединений кремния на поверхности пропанта.

Данные по исследованию механической прочности на истирание образцов по стандартному методу ASTMD-4058 представлены в табл. 3. Видно, что для всех образцов механическая прочность на раздавливание составляет $\geq 10$ МПа. В работах [13-16] показано, что при эксплуатации катализатора в кипящем слое не происходит раскалывание гранул при механической прочности на раздавливание $\geq 10$ МПа. Поэтому можно сделать вывод, что катализаторы на основе модифицированных пропантов обладают достаточной механической прочностью для предотвращения раскола гранул в процессе их эксплуатации в кипящем слое.

\section{Испытание катализаторов}

в процессе сжигания бурого угля в кипящем слое

Известные промышленные катализаторы глубокого окисления ЩКЗ-1, ИК-12-73, ИК-12$74 \mathrm{~A}$ и лабораторные образцы $\mathrm{CuCr}_{2} \mathrm{O}_{4} /$ пропант, $\mathrm{CuCr}_{2} \mathrm{O}_{4} / \Pi \mathrm{M}^{1}, \mathrm{CuCr}_{2} \mathrm{O}_{4} / \Pi^{2}$ были испытаны в процессе сжигания бурого канско-ачинского угля в кипящем слое (табл. 4). Из представленных данных видно, что значения выбросов $\mathrm{CO}$, одного из основных компонентов газификации твердого топлива, существенно отличаются для испытанных катализаторов.

Для катализаторов на основе пропанта эти величины составляют 2200-5000 ppm, что значительно выше, чем для промышленных хромсодержащих катализаторов (320-700 ppm). Тем не менее использование катализаторов на основе пропанта позволяет достичь высоких значе- 
Таблица 4. Результаты исследований катализаторов в процессе сжигания бурого угля в кипящем слое Table 4. The results of studies of catalysts in the process of coal combustion in a fluidized bed

\begin{tabular}{|c|c|c|c|c|}
\hline Образец & Состав & $\begin{array}{c}\text { Содержание } \\
\mathrm{AK} * \% \text { по массе }\end{array}$ & $\begin{array}{c}\text { Содержание СО, } \\
\text { ppm }\end{array}$ & $\begin{array}{c}\text { Степень выгорания } \\
\text { угля, \% }\end{array}$ \\
\hline ЩК3-1 & $\mathrm{CuCr}_{2} \mathrm{O}_{4} / \gamma-\mathrm{Al}_{2} \mathrm{O}_{3}$ & 10,0 & 320 & 95 \\
\hline ИК-12-73 & $\mathrm{CuMgCr}_{2} \mathrm{O}_{4} / \gamma-\mathrm{Al}_{2} \mathrm{O}_{3}$ & 22,3 & 700 & 95 \\
\hline ИК-12-74A & $\mathrm{Fe}_{2} \mathrm{O}_{3} / \gamma-\mathrm{Al}_{2} \mathrm{O}_{3}$ & 4,5 & 2800 & 70 \\
\hline Инертный материал & $\mathrm{SiO}_{2}$ & - & 8000 & 95 \\
\hline $\mathrm{CuCr}_{2} \mathrm{O}_{4} /$ пропант & $\mathrm{CuCr}_{2} \mathrm{O}_{4} / \mathrm{SiO}_{2}-\mathrm{MgO}$ & 2,8 & 5000 & 95 \\
\hline $\mathrm{CuCr}_{2} \mathrm{O}_{4} / П \mathrm{M}^{1}$ & $\mathrm{CuCr}_{2} \mathrm{O}_{4} / \mathrm{SiO}_{2}-\mathrm{MgO}$ & 5,3 & 4200 & 95 \\
\hline $\mathrm{CuCr}_{2} \mathrm{O}_{4} / П \mathrm{M}^{2}$ & $\mathrm{CuCr}_{2} \mathrm{O}_{4} / \mathrm{SiO}_{2}-\mathrm{MgO}$ & 6,3 & 2200 & \\
\hline
\end{tabular}

*Активный компонент.

ний степени выгорания бурого угля, характерных для промышленных катализаторов ( 95 \%). Наиболее активным катализатором является образец $\mathrm{CuCr}_{2} \mathrm{O}_{4} / \Pi^{2}$, что согласуется с данными каталитических испытаний (см. табл. 1).

\section{Выводы}

В настоящей работе рассмотрена возможность использования пропанта в качестве носителя для катализаторов глубокого окисления для кипящего слоя. Было предложено два способа развития удельной поверхности, заключающихся в выщелачивании пропанта в водных растворах гидроксида натрия в жестких и мягких условиях. Было показано, что данные способы позволяют увеличить удельную поверхность и, как следствие, активность в реакции окисления СО медно-хромовых катализаторов на основе пропанта. Комплексом физико-химических методов показано, что в случае выщелачивания пропанта в мягких условиях $\left(3.5 \mathrm{M} \mathrm{NaOH}, 95{ }^{\circ} \mathrm{C}\right)$ происходит растворение преимущественно оксида кремния, а в жестких условиях $(18.0 \mathrm{M} \mathrm{NaOH}$, $120{ }^{\circ} \mathrm{C}$ ) - растворение как оксида кремния, так и силикатов, причем дальнейшая обработка азотной кислотой приводит к формированию аморфной фазы оксида кремния на поверхности модифицированного пропанта.

Испытание катализаторов на основе пропанта показало, что использование данных катализаторов позволяет достичь высоких значений степени выгорания бурого угля, характерных для промышленных катализаторов ( 95 \%), причем для инертного материала это значение составляет $70 \%$. Наиболее низкое значения концентраций $\mathrm{CO}$ в отходящих газах достигается при использовании медно-хромового катализатора $\mathrm{CuCr}_{2} \mathrm{O}_{4} / \mathrm{\Pi M}^{2}$. Причем для данного катализатора значение концентрации СО оказалось на том же уровне, что и при использовании промышленного железосодержащего катализатора ИК-12-74А.

Работа выполнена в рамках государственного задания Института катализа СО РАН (проект АAAA-A17-117041710075-0). 


\section{Список литературы}

1. Simonov A.D., Fedorov I.A., Dubinin Y.V., Yazikov N.A., Yakovlev V.A., Parmon V.N. Catalytic thermal systems for industrial heating Catalytic Heat-Generating Units for Industrial Heating. Catalysis in Industry 2013. Vol. 5, P. 42-49.

2. Патент 826798 СССР. Боресков Г.К., Левицкий Э.А. Способ сжигания топлив. Опубл. 30.05.1983. [Patent 826798 USSR. Boreskov G.K., Levitskij E.A. Method of fuels combustion. Publ. Date 30.05.1983 (In Russ.)]

3. Boreskov G.K. Heterogeneous Catalysis: Nova Biomedical, 2004. 236 p.

4. Yazykov N.A., Simonov A.D., Mishchenko T.I., Aflyatunov A., Smolin S.V., Parmon V.N. Fuel Combustion in the Fluidized Bed of an Inert Material Equipped with an Unmovable Catalytic Small-Volume Package. Chemistry for Sustainable Development. 2003. Vol. 11(1), P. 321-326.

5. Патент 2459852 РФ. Шмотьев С.Ф., Торстен Б. Способ изготовления керамического проппанта и проппант. Опубл. 27.08.2018. [Patent 826798 RU. Shmotyev S.F., Torsten B. The method of ceramic proppant preparation and proppant. Publ. Date 27.08.2012 (In Russ.)]

6. Федоров А.В., Языков Н.А., Ермаков Д.Ю., Булавченко О.А., Яковлев В.А. Исследование полученных методом капельного формования сферических гранул $\mathrm{CuO}-\mathrm{Fe}_{2} \mathrm{O}_{3}-\mathrm{Al}_{2} \mathrm{O}_{3}$ катализатора для процесса сжигания бурого угля в кипящем слое. Катализ в промышленности 2017. № 17, C. 324-330. [Fedorov A.V., Yazykov N.A., Ermakov D.Y., Bulavchenko J.A., Yakovlev V.A. Studies of Spherical Granules of the $\mathrm{CuO}-\mathrm{Fe}_{2} \mathrm{O}_{3}-\mathrm{Al}_{2} \mathrm{O}_{3}$ Catalyst Prepared by Drop Molding for the Process of Fluidized Bed Burning of Brown Coal. Catalysis in Industry 2017. Vol. 17(4), P. 324-330. (In Russ.)]

7. Тамм М.Е., Третьяков, Ю.Д. Неорганическая химия: в 3 т. М.: Издательский центр «Академия», 2012, 240 с. [Tamm M.E., Tretyakov Yu.D. Inorganic chemistry: In 3 volume. Moscow: Publishing Center “Academy”, 2012, 240 p. (In Russ.)]

8. Khassin A.A., Yurieva T.M., Demeshkina M.P., Kustova G.N., Itenberg I.S., Kaichev V.V., Plyasova L.M., Anufrienko V.F., Molina I.Y., Larina T.V., Baronskaya N.A., Parmon V.N. Characterization of the nickel-amesite-chlorite-vermiculite system. Part I. Silicon binding in Ni-MgAl phylloaluminosilicates. Physical Chemistry Chemical Physics 2003. Vol. 5(18), P. 4025-4031.

9. Vinu A., Karthik M., Miyahara M., Murugesan V., Ariga K. ortho-Selective ethylation of phenol with ethanol catalyzed by bimetallic mesoporous catalyst, CoAl-MCM-41. Journal of Molecular Catalysis A: Chemical 2005. Vol. 230(1-2), P. 151-157.

10. Kim S., Kim M.C., Choi S.-H., Kim K.J., Hwang H.N., Hwang C.C. Size dependence of $\mathrm{Si}_{2 \mathrm{p}}$ core-level shift at $\mathrm{Si}$ nanocrystal/ $/ \mathrm{SiO}_{2}$ interfaces. Applied Physics Letters 2007. Vol. 91(10), P. 103-113.

11. Nesbitt H.W., Bancroft G.M., Henderson G.S., Ho R., Dalby K.N., Huang Y., Yan Z. Bridging. Bridging, non-bridging and free $\left(\mathrm{O}^{2-}\right)$ oxygen in $\mathrm{Na}_{2} \mathrm{O}-\mathrm{SiO}_{2}$ glasses: An X-ray Photoelectron Spectroscopic (XPS) and Nuclear Magnetic Resonance (NMR) study. Journal of Non-Crystalline Solids 2011. Vol. 357(1), P. 170-180.

12. Li K., Wang R., Chen J. Hydrodeoxygenation of Anisole over Silica-Supported $\mathrm{Ni}_{2} \mathrm{P}$, MoP, and NiMoP Catalysts. Energy \& Fuels 2011. Vol. 25(3), P. 854-863.

13. Исмагилов 3.Р., Елисеева Л.Ф., Шкрабина Р.А., Шепелева М.Н., Кириченко О.А., Ушаков В.А., Петров А.С. Выбор методики определения механической прочности носителей и 
катализаторов для каталитических генераторов тепла. Научные основы приготовления катализаторов: Тез. докл. Всесоюзного совещуания, Новосибирск, 1983. C. 262. [Ismagilov Z.R., Eliseeva L.F., Shkrabina R.A., Shepeleva M.N., Kirichenko O.A., Ushakov V.A., Petrov A.S. The choice of methods for determining the mechanical strength of supports and catalysts for catalytic heat generators. Scientific basis for the preparation of catalysts: Abstracts. Novosibirsk, 1983 p. 262 (In Russ.)]

14. Исмагилов, 3.Р., Шепелева, М.Н., Шкрабина, Р.А. Особенности образования механически прочных сферических гранул $\mathrm{Al}_{2} \mathrm{O}_{3}$ при жидкостном формовании. Проблемы прочности гранулированных носителей и катализаторов: Материаль Всесоюз. совещ., Новосибирск. 1989. C. 40-49. [Ismagilov Z.R., Shepeleva M.N., Shkrabina R.A. Features of the formation of mechanically strong spherical $\mathrm{Al}_{2} \mathrm{O}_{3}$ granules by oil-drop method. The strength problems of granular supportsand catalysts: Abstract. Novosibirsk. 1989. P. 40-49. (In Russ.)]

15. Шкрабина Р.А. Закономерности формирования и регулирования физико-химических и структурно-механических свойств сферических алюмооксидных носителей: Автореф. дис. ... канд. хим. наук. Институт катализа им. Г. К. Борескова. Новосибирск, 1997. [Shkrabina R.A. Patterns of formation and regulation of physico-chemical and structural-mechanical properties of spherical alumina supports: PhD thesis. Novosibirsk, Boreskov Institute of Catalysis, 1997. (In Russ.)]

16. Корябкина Н.А. Научные основы приготовления и разработка способа получения высокопрочных магнийсодержащих алюмооксидных носителей: Автореф. дис. ... канд. хим. наук. Институт катализа им. Г.К. Борескова. Новосибирск, 1992. [Koryabkina N.A. Scientific basis for the preparation and development of a method for producing high-strength magnesium-containing alumina supports: PhD thesis. Novosibirsk. Boreskov Institute of Catalysis, 1992. (In Russ.)] 